\title{
DETERMINATION OF VELOCITY SEAL AREA REDUCTION BASED ON PURGE GAS FLOW RATE AND PRESSURE DROP IN FLARE SYSTEM
}

\begin{abstract}
Akash Kumar
Department of Design and Engineering

Ador Welding Limited (PEB), Pune, Maharashtra, India

Abstract - Purge gas is required in flare system to avoid air ingress in the stack through tip and to reduce the amount of flow of purge gas velocity or molecular seal is used. To determine the amount of reduction of purge gas in velocity seal, a simulation model has been created. This model predicted the optimum amount of baffle to tip area reduction by taking oxygen content, pressure drop and purge rate into account. The results show there is a significant impact of baffle size on the oxygen content in the flare system. Different velocity seal model viz. 40, 50, 60 and 70 were created and it is found that when the baffle to tip area reduction was $50 \%$, there was an optimum amount of purge rate required with limited pressure drop occurrence and the most importantly the oxygen distribution below the seal was less than $6 \%$ which is half the vol.\% required for combustion. Therefore $d / D=0.7$ to 0.78 was the optimum design as per our study. But if the purge rate is maintained by API-521 i.e. $0.012 \mathrm{~m} / \mathrm{s}$, the ratio d/D should not be greater than 0.75 .
\end{abstract}

Keywords - Purge rate, Velocity seal, Burn back, flare system.

\section{INTRODUCTION}

In order to prevent problems like explosion and burn back in operation of flare systems, safe amount of purge gas is required which needs to be an oxygen free gas generally called as inert gas. Purge gas (or "purge flow") is required to prevent air impingement in the process header when there is little or no process flow going to the flare (as in the case of a dedicated intermittent or ESD flare). Should air enter the flare stack, a release of process gas could result in a combustible mixture present within the flare in a restricted zone.

For safety purposes, a pre-commissioning purge and subsequent purge is required through the flare system [1]. During startup, there are some possibilities that oxygen get accumulated in the system which creates hazardous explosion, and hence the pre-commissioning purge displaces any existing air from the stack and continuous purge ensures that atmospheric air does not enter the stack through the tip. As discussed above, the air present in the stack can create a potentially explosive mixture with incoming flare gas. So, to avoid or eliminate such condition gas seals usually located at/
Sachin Phadatare, Pradeep Deore

Department of Design and Engineering

Ador Welding Limited (PEB), Pune, Maharashtra, India

or below the flare tip are used: Molecular seal and Velocity seal. These seals are used to reduce the purge gas requirement and it is proven that molecular seal reduces the amount of purge gas by $98 \%$ approximately but it is not so in case of velocity seal. There is a significant increase in purge gas requirement in case of velocity seal and for which it was suggested to reduce the same to an extent so that the usage of such seal become efficient. The most important operating parameter of a velocity seal is the purge gas flow rate. A purge rate that is too high leads to an increase in operating costs; a purge rate that is too low may cause burn back and explosions in the stack. In April 2008, an explosion occurred in a flare system at a refinery in China after emergency relief involving a hydro treating unit. The reason was the low purge rate [2]. Therefore, an optimization is needed in such case; the very first step in this field of optimization was made by Husa [3], who proposed a formula for determining the purge rate needed to maintain required oxygen content in the stack. API 521 [1] suggests the purge gas velocity through the tip between 0.006 $\mathrm{m} / \mathrm{s}$ to $0.012 \mathrm{~m} / \mathrm{s}$ which keeps the oxygen concentrations below the seal to $4 \%$ to $8 \%$ which is $50 \%$ of the limiting oxygen concentration required to create a flammable mixture. The aim of our work is to propose a best model for the safe purge rate by analyzing oxygen distribution and pressure drop in velocity seal for different area reduction.

\section{RESULTS AND DISCUSSION}

The velocity seal also known as Diode Pinecone dynamic seal (DPCS) is the simplest of purge reduction seals and takes the form of a truncated cone normally made as an integral part of the flare tip. It provides the flare system with a physical barrier to air penetration down the inside wall of the riser and also maximizes the velocity of the purge gas, further reducing the risk of air ingress. It was assumed that the purge rate and oxygen content depends on the Baffle to tip diameter ratios and on the basis of the same analysis was proposed.

The DPCS designed by Ador welding is equipment designed and developed in the course of its long experience in the field of flares. As discussed above, it is built of a system of conical spoilers to create a gas flow ring like venturi. The performance of the same is based on a dynamic effect (Fig.1.) due to the flow of a purge gas through it producing an air reversal due to: 


\section{International Journal of Engineering Applied Sciences and Technology, 2020 \\ Vol. 4, Issue 10, ISSN No. 2455-2143, Pages 45-48 \\ Published Online February 2020 in IJEAST (http://www.ijeast.com)}

- Wind dynamic action

- Gas contraction following temperature decreasing

- Atmospheric inversion

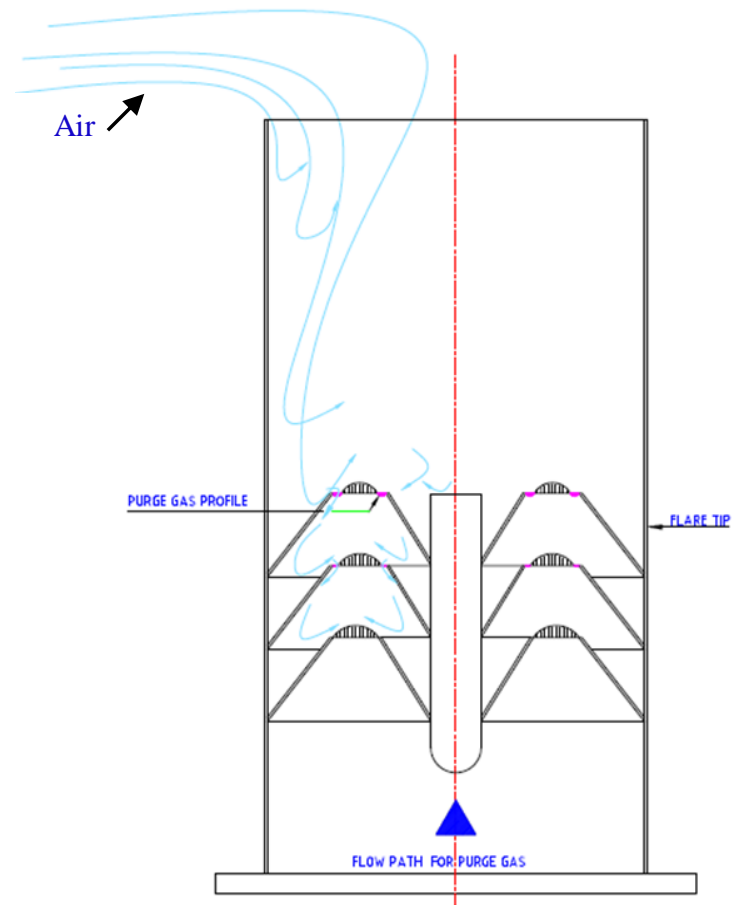

Fig.1. Ador Diode Pinecone Seal

The major part of design is based on the different models which correspond to different baffle to tip diameters ratios as shown in fig. 2 .

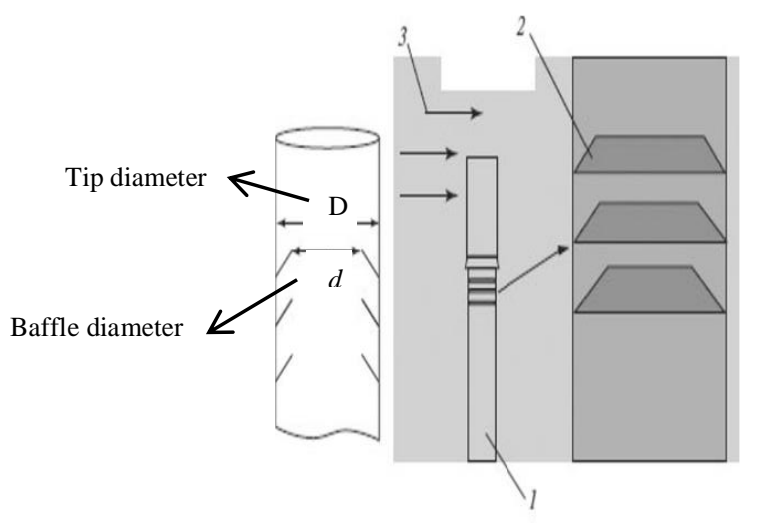

Fig.2. Velocity seal simulation model: 1) Flare stack; 2) Baffles; 3) Wind [4]

Ador's velocity seal designs consist of different models as explained earlier viz. Model 40, 50, 60 and 70. These models are defined on the basis of area reduction i.e. tip area to seal/baffle area. For example, Model 40 will have $60 \%$ reduction in area of the tip. Each model has its own minimum purge gas flow rate and pressure drop, as shown in the table, comparative to the model 50 , considering at $100 \%$ pressure drop and purge flow:

\begin{tabular}{|ccccc|}
\hline Model & 40 & 50 & 60 & 70 \\
\hline $\begin{array}{c}\text { Pressure } \\
\text { drop }\end{array}$ & 165 & 100 & 65 & 40 \\
\hline $\begin{array}{c}\text { Purge } \\
\text { gas }\end{array}$ & 80 & 100 & 120 & 140 \\
\hline
\end{tabular}

Therefore, the selection between these models needed wide range of clarification regarding oxygen content at the specified velocities as per API 521. Yong- Zhong Bai et.al calculated the oxygen concentration in the velocity seal for purge rate $0.012 \mathrm{~m} / \mathrm{s}$ and baffle to seal dimeter ratio $\mathrm{d} / \mathrm{D}=0.92$ which shows that close to the lower boundary of the seal, the oxygen concentration exceeds $6 \mathrm{vol} \%$ which suggested a risk of burnback and explosion in the flare stack. Since the key components of a velocity seal are the baffles, the optimizing process was focused on the baffles diameter. Therefore several $\mathrm{d} / \mathrm{D}$ ratio was considered and it was found that for $\mathrm{d} / \mathrm{D}=0.7$, the average oxygen concentration at the bottom of seal is 5.6 $\%$ which is $0.4 \%$ less than the safe oxygen concentration.

The purge rate for different tip size for different models of velocity seal is shown in Fig.3.

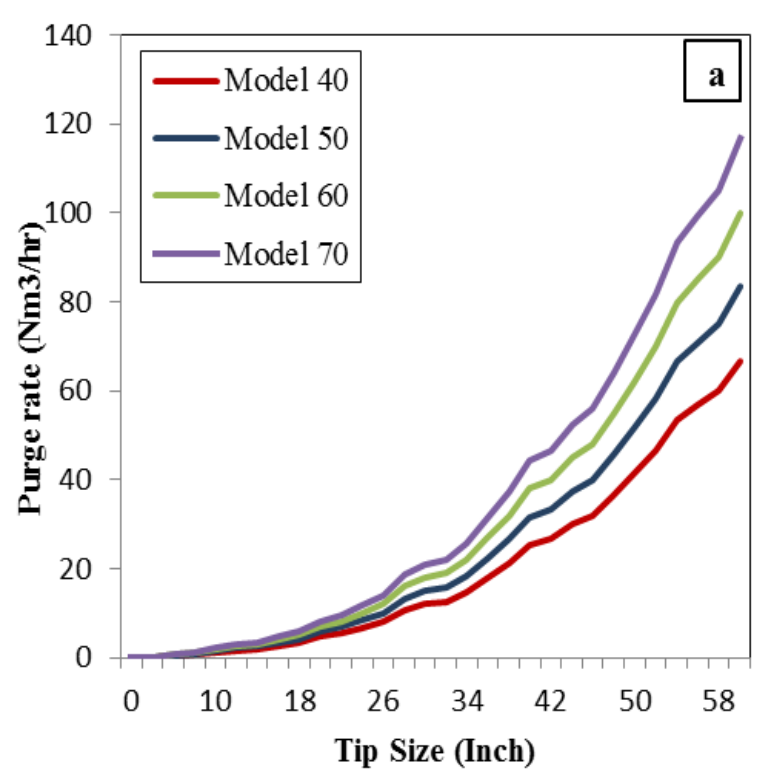




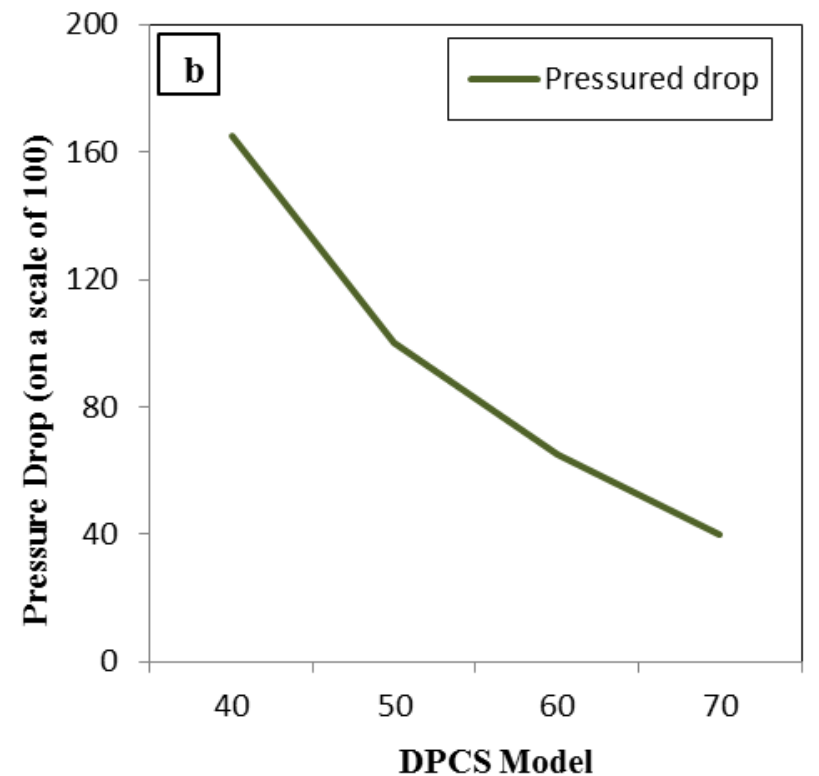

Fig.3. Evaluation of Velocity seal on the basis of Model a) Purge rate for different tip size, b) Pressure drop on scale of 100 for different models

It can be seen from above figure that the purge rate is very less in the case of Model 40 but at the same time pressure drop is very large and so the velocity which can cause flame lift off. And as per Yong- Zhong Bai et.al, it is not recommended to use this model as the oxygen content exceeds the flammable limit. Fig. 4 shows burn back velocities for different purge rates for a basic flare tip. It can be clearly seen that at low purge rates the flame burn back takes place and the same can be considered while selecting the model of velocity seal.

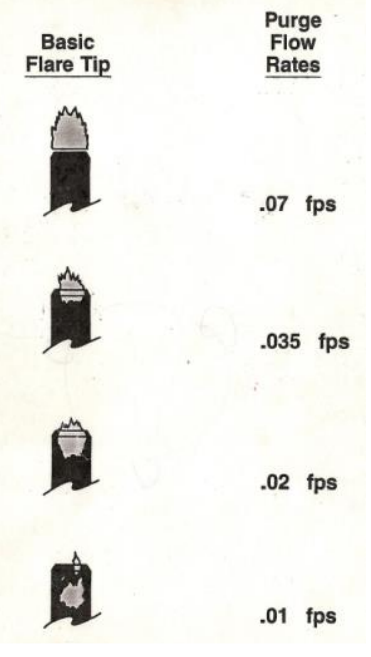

Fig.4. Burn-back velocities with Methane purge
The different velocity seal models exhibit different properties w.r.t purge flow rate, pressure drop and oxygen content. Larger the reduction in area more is the pressure drop and hence less purge requirement. On the basis of these observations, Ador diode pinecone seal has the following advantages:

- Completely built in stainless steel material with no corrosion problem

- No possibility of rain or condensate collection since the spoilers are self-draining

- No moving parts

- Purge gas saving

- It gives good performance also if installed in horizontal position since it is not based on gravity principle

- The central support pipe as shown in fig.1. can also be used for steam injection inside the tip when required to give a smokeless operation

- Less weight and cost if compared with other gravity systems.

\section{CONCLUSION}

This velocity seal has been installed by Ador on over 200 flare tips with sizes up to 82 inches, with good performance and based on this following conclusion can be drawn:

1. The baffle size has a significant impact on the oxygen distribution in a velocity seal.

2. For a purge rate of $0.012 \mathrm{~m} / \mathrm{s}$ as recommended by API 521, the baffle to tip diameter ratio should not be more than 0.7 when hydrocarbons are burned in the flare.

3. Baffle size in velocity seal model 40 is insufficient for forcing out all the air entering the flare stack for purge rate $0.012 \mathrm{~m} / \mathrm{s}$. Consequently, in order to prevent infiltration of air into flare stack for low purge rate, different other models were created.

4. Of the 4 models, Model 50 is the optimized one and can be taken up to Model 60 only. Other two models are not efficient due to large amount of oxygen content below the seal and large pressure drop.

5. There is no decisive impact of purge flow rate when the diameter of the tip is below 18 inch and hence the selection of $\mathrm{d} / \mathrm{D}$ is independent of flow rate upto 18 inch.

\section{REFERENCE}

[1] API Standard 521, Sixth edition, (January 2014): Pressure relieving and depressurizing systems.

[2] W. Y. Dang and A. F. Yu (2010), "Study on the design pressure for water-sealed drum in refinery flare system," China Safety Science Journal, 20, No. 9, 75-80.

[3] H. W. Husa, "How to compute safe purge rates," Hydrocarbon Processing and Petroleum Refiner, 43, This 
work was supported by the National Basic Research Program of China (program 973), grant No. 2010CB226902.

[4] Yong-Zhong Bai, Peng Wang, and Jun-cheng Jiang January, 2014: Determination of the minimum purge gas flow rate in flare systems with a velocity seals, Chemistry and Technology of Fuels and Oils, Vol. 49, No. 6, (Russian Original No. 6, November- December, 2013).

[5] API standard 537, second edition, (December 2008): Flare details for general refinery and petrochemical service.

[6] W. C. Bluhm, "Safe Operation of Refinery Flare Systems," API Proceedings, Volume 41, API, Washington, DC, 1961.

[7] G. Armistead, Jr., Safety in Petroleum Refining and Related Industries, Second Edition, John G. Simmonds, New York, 1959.

[8] D. Shore (1996), "Making the flare safe," Journal of Loss Prevention in the Process Industries, 9, No. 6, 363-381.

[9] S. H. Tan (1967), "Flare system design simplified," Hydrocarbon Processing, 46, 172-176.

[10] V. I. Panchenko (1993), "Determining the safe purge rates for flare tubes," Chemical and Petroleum Engineering, 29, No. 5, 205-209.

[11] H. W. Husa (1977), Purging Requirements of Large Diameter Stacks, paper presented at the Fire/Safety Engineering Subcommittee of the American Petroleum Institute, Fall 1977 Meeting, September 13-15, San Francisco, California.

[12] G. R. Kent (1964), "Practical Design of Flare Stacks," Hydrocarbon Processing and Petroleum Refiner, Volume 43, Number 8, pp. 121-125. 